\title{
Vasodilatory Effect of Arginine Vasopressin Is Mediated by Nitric Oxide in Human Forearm Vessels
}

\author{
Tatsuya Tagawa, Tsutomu Imaizumi, Toyonari Endo, Masanari Shiramoto, \\ Yoshitaka Hirooka, Shin-ichi Ando, and Akira Takeshita \\ Research Institute of Angiocardiology and Cardiovascular Clinic, Faculty of Medicine, Kyushu University, Fukuoka 812, Japan
}

\begin{abstract}
Arginine vasopressin (AVP) causes biphasic changes in vascular resistance in human forearms; vasoconstriction at lower doses and vasodilation at higher doses. Vasoconstriction is mediated by the V1 receptor. However, the mechanism of AVP-induced vasodilation is not known. We investigated whether AVP-induced vasodilation is mediated by nitric oxide (NO) in human forearms by examining the effects of $\mathrm{L}$-arginine (a precursor of NO) and $N^{G}$-monomethyl-L-arginine (L-NMMA, a blocker of NO synthase) on AVP-induced vasodilation. AVP was infused intraarterially at doses of $0.05,0.1,0.2,0.5$, and 1.0 $\mathrm{ng} / \mathrm{kg}$ per $\min (n=8)$. The lower doses of AVP $(\leq 0.1 \mathrm{ng} / \mathrm{kg}$ per min) increased, whereas the higher doses of AVP $(\geq 0.5$ $\mathrm{ng} / \mathrm{kg}$ per $\mathrm{min}$ ) decreased forearm vascular resistance (FVR) $(P<0.01)$. Intraarterially infused $\mathrm{L}$-arginine at $10 \mathrm{mg} / \mathrm{min}$ did not alter arterial pressure, baseline FVR, or heart rate. L-arginine did not alter the magnitude of AVP-induced vasoconstriction at the lower doses, but L-arginine augmented the magnitude of AVP-induced vasodilation at doses of $0.2(P<0.05)$, $0.5(P<0.01)$, and $1.0(P<0.05) \mathrm{ng} / \mathrm{kg}$ per $\mathrm{min}$. In another group $(n=6)$, intraarterially infused L-NMMA $(4 \mu \mathrm{mol} / \mathrm{min}$ for $5 \mathrm{~min}$ ) increased baseline FVR without systemic effects, and inhibited acetylcholine-induced vasodilation $(P<0.01)$. L-NMMA at this dose inhibited AVP-induced vasodilation ( $P$ $<0.01$ ) but did not affect vasoconstriction. $L$-arginine reversed the inhibitory effect of L-NMMA. Our results suggest that the vasodilatory effect of AVP may be mediated by NO in human forearms. (J. Clin. Invest. 1993. 92:1483-1490.) Key words: L-arginine $\bullet$ endothelium-derived relaxing factor $\bullet \mathbf{N}^{\mathbf{G}}$-monomethyl-L-arginine • plethysmography • human study
\end{abstract}

\section{Introduction}

It has been believed for long time that arginine vasopressin $(\mathrm{AVP})^{1}$ is a potent vasoconstrictor $(1,2)$. However, recent studies in humans have demonstrated that the effects of AVP

Address correspondence to Tsutomu Imaizumi, M.D., Research Institute of Angiocardiology and Cardiovascular Clinic, Faculty of Medicine, Kyushu University, 3-1-1 Maidashi, Higashi-ku, Fukuoka 812, Japan.

Received for publication 16 February 1993 and in revised form 5 May 1993.

1. Abbreviations used in this paper: AVP, arginine vasopressin; FBF, forearm blood flow; FVR, forearm vascular resistance; L-NMMA, $N^{\mathrm{G}}$ monomethyl-L-arginine; MBP, mean blood pressure; NO, nitric oxide.

J. Clin. Invest.

(c) The American Society for Clinical Investigation, Inc.

0021-9738/93/09/1483/08 \$2.00

Volume 92, September 1993, 1483-1490 on forearm resistance arteries are biphasic $(3,4)$. Intraarterially infused AVP at lower doses causes vasoconstriction, and AVP at higher doses causes vasodilation $(3,4)$. AVP-induced vasoconstriction is mediated by the $\mathrm{V} 1$ receptor because it is inhibited by a specific V1 receptor antagonist $(4,5)$. However, the mechanism of AVP-induced vasodilation is not known.

Recently, it has been well accepted that the endothelium plays an important role in control of vascular tone. Nitric oxide (NO) is produced in the process of conversion of a semi-essential amino acid, L-arginine, to L-citrulline by NO synthase in endothelial cells (6-9). NO is one of endothelium-derived relaxing factors. NO is a potent and direct activator of soluble guanylate cyclase and increases $3^{\prime}, 5^{\prime}$ monophosphate (cGMP) (10-12), which causes vasodilation. Acetylcholine-induced vasodilation in the human forearm is mediated by NO since the vasodilation is inhibited by $N^{\mathrm{G}}$-monomethyl-L-arginine ( $\mathrm{L}$ NMMA), a specific inhibitor of NO as well, and augmented by supplementation of L-arginine $(13,14)$.

In vitro, it has been shown in several experiments that AVP causes vasodilation (15-18), that the vasodilation is inhibited by pretreatment with L-NMMA, and that pretreatment with L-arginine prevented the inhibitory effects of L-NMMA (18). These results suggest that vasodilation by AVP is probably mediated by NO in animals. It is possible that AVP-induced vasodilation in humans also is mediated by NO. However, this possibility has not been examined.

In this study, we investigated the possibility that AVP-induced vasodilation is mediated by NO in human forearm vessels. First, we infused small amounts of AVP intraarterially into the brachial artery while measuring forearm blood flow (FBF). AVP caused vasoconstriction at lower doses and caused vasodilation at higher doses. Second, we determined whether supplementation of L-arginine augmented AVP-induced vasodilation. Third, we determined whether L-NMMA inhibited AVP-induced vasodilation. Fourth, we determined whether L-arginine reversed the inhibitory effects of L-NMMA.

\section{Methods}

General procedure. Subjects were all young, healthy male students (2128 yr old ) at our university who volunteered for the study. The protocol was explained, and informed written consent was obtained from each subject. The study was approved by Ethical Committee for Human Study in our institution. The study was done with subjects in a supine position and in an air-conditioned room with room temperature of $\sim 25-26^{\circ} \mathrm{C}$. Under local anesthesia with $2 \%$ procaine, the left brachial artery was cannulated with a 20 -gauge intravascular over the needle poly(tetrafluoroethlene) catheter (Quick-Cath; Travenol Laboratories, Inc., Baxter Healthcare Corp., Deerfield, IL) for drug infusion. The catheter was connected by a three-way stopcock to a pressure transducer (Viggo-Spectramed, Oxnard, CA) for direct measurement of arterial pressure. The arterial line was kept open by infusing heparinized saline $(0.1 \mathrm{ml} / \mathrm{min})$ when no drug was being administered. In some subjects, a vein in the antecubital region of the ispilateral arm was 
cannulated with the same cannula as used for the artery to obtain blood samples for measuring plasma levels of AVP and L-arginine. Heart rate was obtained by counting pulse rate for a few minutes on arterial pressure recordings.

Measurements of forearm blood flow. Forearm blood flow was measured by using a mercury in silastic strain gauge plethysmograph with a venous occlusion technique $(19,20)$. The strain gauge was placed $\sim 5$ $\mathrm{cm}$ below the antecubital crease. Forearm blood flow (milliliters per minute per $100 \mathrm{ml}$ forearm) was calculated from the rate of increase in forearm volume, while venous return from the forearm was prevented by inflating the cuff on the upper arm. The pressure in the venous occlusion or congesting cuff on the upper arm was $40 \mathrm{mmHg}$. Circulation to the hand was arrested by inflating a cuff around the wrist. The wrist cuff was inflated before the determination of forearm blood flow and continuously throughout the measurements. Forearm vascular resistance was calculated by dividing the mean arterial pressure (diastolic pressure plus one third of the pulse pressure in millimeters of mercury) by the forearm blood flow. These values are expressed as units throughout this report. An average of four flow measurements made 15-s intervals, which were calculated by two authors independently, was used for later analysis.

Forearm vascular responses to drugs. After the placement of cannulae and a strain gauge plethysmograph, $\geq 15 \mathrm{~min}$ were allowed for subjects to become accustomed to the study condition before the experiments were begun.

Four experimental protocols were performed. In the first protocol, we determined responses of forearm blood flow to intraarterially in fused AVP at graded doses before and after L-arginine or D-arginine ( $n$ $=8$ ). First, we examined forearm responses of forearm blood flow to intraarterially infused AVP at $0.05,0.1,0.2,0.5$, and $1.0 \mathrm{ng} / \mathrm{kg}$ per min for $2 \mathrm{~min}$ at each dose. Forearm blood flow and arterial pressure were continuously monitored and recorded. At least $15 \mathrm{~min}$ after the final dose of AVP, when forearm blood flow had returned to the baseline level, intraarterial infusion of D-arginine was started and continuously infused at a dose of $10 \mathrm{mg} / \mathrm{min}$. The baseline measurements of forearm blood flow, arterial pressure, and heart rate were obtained $15 \mathrm{~min}$ after infusion of D-arginine. While infusion of D-arginine at $10 \mathrm{mg} / \mathrm{min}$, AVP was infused intraarterially in the same way as before D-arginine. Forearm hemodynamic measurements were repeated as described above. After recovery, infusion of L-arginine was similar performed described as above. Forearm hemodynamic measurements were repeated as described above.

In another group of subjects $(n=6)$, the second protocol was performed. Because AVP at higher doses caused vasodilation in the first protocol, we examined whether pretreatment with L-NMMA blocked the vasodilator effects of AVP. We examined responses of forearm blood flow to intraarterially infused acetylcholine at 4 and $12 \mu \mathrm{g} / \mathrm{min}$ or AVP at $0.1,0.5$, and $1.5 \mathrm{ng} / \mathrm{kg}$ per min for $2 \mathrm{~min}$ at each dose. Series of infusions of acetylcholine and those of AVP were alternated. At least 15 min later, when forearm blood flow had returned to the baseline value, L-NMMA was infused at $4 \mu \mathrm{mol} / \mathrm{min}$ for $5 \mathrm{~min}$. Then acetylcholine or AVP was infused immediately after stopping L-NMMA in the same way as before infusion of L-NMMA. Forearm blood flow and arterial pressure were continuously monitored and recorded during infusion of drugs.

The third protocol was performed in five subjects after the second protocol was finished. In this protocol, we determined whether the effects of L-NMMA were reversed with L-arginine. After finishing the second protocol and the parameters had returned to the baseline values, we determined responses of forearm blood flow to intraarterially infused AVP at $1.5 \mathrm{ng} / \mathrm{kg}$ per min for $2 \mathrm{~min}$. After the parameters had returned to the baseline values, L-NMMA was infused at $4 \mu \mathrm{mol} / \mathrm{min}$ for $5 \mathrm{~min}$. Then AVP was immediately infused in the same way as before infusion of L-NMMA. After $\geq 15 \mathrm{~min}$, when the forearm blood flow had returned to the baseline value, L-NMMA $(4 \mu \mathrm{mol} / \mathrm{min})$ and L-arginine $(8 \mathrm{mg} / \mathrm{min})$ were simultaneously infused for $5 \mathrm{~min}$, and then AVP was infused in the same way as before infusion of L-NMMA.
Forearm blood flow and arterial pressure were continuously monitored and recorded during infusion of drugs.

The fourth protocol was performed in the third group of subjects ( $n$ $=5$ ). In this protocol, we determined whether responses to AVP were altered over a period of $2 \mathrm{~h}$. First, we examined responses of forearm blood flow to intraarterially infused AVP at $0.05,0.1,0.2,0.5$, and 1.0 $\mathrm{ng} / \mathrm{kg}$ per $\mathrm{min}$ for $2 \mathrm{~min}$ at each dose. Forearm blood flow and arterial pressure were continuously monitored and recorded. Within $2 \mathrm{hs}$, the same protocol was repeated three times.

The total duration of the experiment in a subject did not exceed $2 \mathrm{~h}$ and $30 \mathrm{~min}$. The infusion volume did not exceed $0.6 \mathrm{ml} / \mathrm{min}$. We had confirmed that this volume of infusion itself did not alter forearm blood flow $(19,20)$. The last 1 min of measurements of forearm blood flow during infusion of each dose of the drug was used for later analysis.

Measurements of plasma arginine vasopressin and L-arginine. In seven subjects, $5 \mathrm{ml}$ blood was drawn for measurements of AVP during the control period and during infusion of AVP at the dose of $1.0 \mathrm{ng} / \mathrm{kg}$ per min. Blood was sampled into a tube containing EDTA-2K $(1 \mathrm{mg} /$ $\mathrm{ml}$ ). In seven subjects, $5 \mathrm{ml}$ blood was drawn for measurements of $\mathrm{L}$-arginine during control period and during infusion of $\mathrm{L}$-arginine at dose of $10 \mathrm{mg} / \mathrm{min}$. Blood samples were centrifuged immediately and stored in a freezer at $-20^{\circ} \mathrm{C}$. Plasma AVP and L-arginine were measured at a commercially available laboratory (SRL, Tokyo, Japan). Plasma AVP was measured in duplicate by RIA kits obtained from Mitsubishi Petrochemical Co. Ltd. (Tokyo, Japan), after Sep-Pak C18 extraction of plasma as previously described $(21,22)$. The crossreactivity of antiserum with 8 -lysine vasopressin was $0.04 \%$; it was $0.19 \%$ with 1-deamino-8-D-arginine vasopressin and $<0.01 \%$ with oxytosin and 8 -arginine vasotocin. The sensitivity of the assay was $0.06 \mathrm{fg} / \mathrm{ml}$. The recovery of AVP ranged from 79.3-99.4\% at AVP concentrations of $0.50-8.00 \mathrm{pg} / \mathrm{ml}$ plasma; the results were corrected for recovery. The intra- and interassay coefficients of variation were $7.8 \%$ and $7.4 \%$, respectively, for AVP concentrations of 1.15 and $1.50 \mathrm{pg} / \mathrm{ml}$. Plasma L-arginine was measured by high performance liquid chromatography. The analyses were performed in a high performance analyzer (System 6300; Beckman Instruments, Inc., Fullerton, CA) equipped with a data integrator (model 7000; Systems Instruments Corporation of America, Santa, CA) (23). For a calibration standard mixture of 1.0 and 2.5 $\mathrm{nmol} / 50 \mu \mathrm{l}$, the average $\mathrm{CV}$ in the measured areas was $1.4 \%$ and $1.6 \%$, respectively.

Preparation of drugs. Synthetic AVP (20 pressor U/ml) (Pitressin, arginine vasopressin; Parke-Davis, Inc., Morris Plains, NJ) was dissolved in physiological saline immediately before use. For the infusion of L-arginine, commercially available $\mathrm{L}$-arginine solution $(0.1 \mathrm{~g}$ of $\mathrm{L}$-arginine/ml, Morishita Pharmaceutical, Osaka, Japan) was used. D-Arginine was obtained from Sigma Chemical Co. (St. Louis, MO) and prepared similarly to L-arginine at the pharmacological section in our hospital. L-NMMA was obtained from Clinalfa AG (Bahnhofstrasse, Switzerland). Because acetylcholine is unstable in solution, $100 \mathrm{mg}$ acetylcholine (Daiichi Pharmaceutical, Tokyo, Japan) was lyophilized and stored in a vial $(0.4 \mathrm{mg}$ acetylcholine per vial $)$. It was dissolved in physiological saline $(10 \mathrm{ml})$ immediately before use.

Statistical analysis. The hemodynamic values during infusions of AVP, acetylcholine, L-arginine, D-arginine, and L-NMMA were compared by one-way ANOVA for repeated measures to test treatment effects. The hemodynamic responses to AVP before and during infusion of $\mathrm{L}$ - or D-arginine at $10 \mathrm{mg} / \mathrm{min}$ were compared by two-way ANOVA. The hemodynamic responses to AVP or acetylcholine before and after infusion of L-NMMA at $4 \mu \mathrm{mol} / \mathrm{min}$ were compared by twoway ANOVA. The hemodynamic responses to AVP at $1.5 \mathrm{ng} / \mathrm{kg}$ per min before, after L-NMMA at $4 \mu \mathrm{mol} / \mathrm{min}$, or L-NMMA plus L-arginine at $8 \mathrm{mg} / \mathrm{min}$ were compared by one-way ANOVA. The three dose-response curves to AVP in the fourth protocol were compared by two-way ANOVA. When significantly different by one-way or two-way ANOVA, they were compared by paired or unpaired $t$ test to determine the location of difference. All values are expressed as means \pm SEM and $P<0.05$ was to be statistically significant. 
Table I. Forearm Vascular Responses to Intraarterial Infusion of Arginine Vasopressin before and after L-Arginine $(n=8)$

\begin{tabular}{|c|c|c|c|c|c|c|c|}
\hline & Control & $\begin{array}{l}\text { AVP } \\
0.05\end{array}$ & $\begin{array}{c}\text { AVP } \\
0.1\end{array}$ & $\begin{array}{c}\text { AVP } \\
0.2\end{array}$ & $\begin{array}{c}\text { AVP } \\
0.5\end{array}$ & $\begin{array}{c}\text { AVP } \\
1.0\end{array}$ & $\begin{array}{c}P \text { by } \\
\text { two-way } \\
\text { ANOVA }\end{array}$ \\
\hline & & $n g / k g$ per min & $n g / k g$ per min & $n g / k g$ per min & $n g / k g$ per min & $n g / k g$ per min & \\
\hline \multicolumn{8}{|l|}{ MBP (mmHg) } \\
\hline Before L-A & $91 \pm 3$ & $90 \pm 4$ & $90 \pm 4$ & $90 \pm 4$ & $91 \pm 3$ & $93 \pm 4$ & \multirow{2}{*}{ NS } \\
\hline After L-A & $89 \pm 4$ & $90 \pm 4$ & $90 \pm 4$ & $90 \pm 4$ & $91 \pm 4$ & $93 \pm 4$ & \\
\hline \multicolumn{8}{|c|}{ Heart rate (bpm) } \\
\hline Before L-A & $62 \pm 3$ & $61 \pm 3$ & $60 \pm 3$ & $60 \pm 4$ & $59 \pm 4$ & $55 \pm 3$ & \multirow{2}{*}{ NS } \\
\hline After L-A & $60 \pm 3$ & $60 \pm 3$ & $59 \pm 3$ & $61 \pm 3$ & $57 \pm 4$ & $58 \pm 4$ & \\
\hline \multicolumn{8}{|c|}{$\mathrm{FBF}(\mathrm{ml} / \mathrm{min}$ per $100 \mathrm{ml})$} \\
\hline Before L-A & $3.5 \pm 0.3$ & $2.8 \pm 0.3$ & $2.4 \pm 0.2$ & $3.4 \pm 0.3$ & $4.2 \pm 0.4$ & $4.5 \pm 0.4$ & \multirow{2}{*}{$P<0.01$} \\
\hline After L-A & $3.2 \pm 0.4$ & $2.3 \pm 0.2$ & $2.5 \pm 0.3$ & $3.8 \pm 0.4$ & $4.9 \pm 0.7$ & $5.7 \pm 0.8$ & \\
\hline \multicolumn{8}{|l|}{ FVR (U) } \\
\hline Before L-A & $26.4 \pm 1.7$ & $33.5 \pm 2.5$ & $38.6 \pm 3.0$ & $27.7 \pm 2.3$ & $22.8 \pm 1.7$ & $21.2 \pm 1.1$ & \multirow{2}{*}{$P<0.01$} \\
\hline After L-A & $29.4 \pm 3.0$ & $41.2 \pm 4.0$ & $39.6 \pm 5.6$ & $25.5 \pm 2.9$ & $20.6 \pm 2.5$ & $17.9 \pm 1.9$ & \\
\hline \multicolumn{8}{|l|}{ Percent FVR } \\
\hline Before L-A & 100 & $127 \pm 4$ & $147 \pm 6$ & $106 \pm 7$ & $88 \pm 5$ & $82 \pm 5$ & \multirow{2}{*}{$P<0.01$} \\
\hline After L-A & 100 & $144 \pm 10$ & $132 \pm 10$ & $87 \pm 8$ & $72 \pm 8$ & $65 \pm 9$ & \\
\hline
\end{tabular}

Control, during infusion of saline; L-A, L-arginine; MBP, mean blood pressure. Values are mean \pm SEM.

\section{Results}

Responses to intraarterial infusion of arginine vasopressin ( $\mathrm{Ta}$ ble I). Intraarterial infusion of AVP $(n=8)$ caused biphasic changes in forearm blood flow. AVP decreased forearm blood flow at lower doses $(0.05$ and $0.1 \mathrm{ng} / \mathrm{kg}$ per $\mathrm{min})$ and decreased forearm blood flow at higher doses $(\geq 0.5 \mathrm{ng} / \mathrm{kg}$ per $\mathrm{min})(P$ $<0.01$ ) (Fig. 1). Arterial pressure or heart rate was not altered during infusion of AVP (Table I). Intraarterial infusion of AVP at doses of $1.0 \mathrm{ng} / \mathrm{kg}$ per $\min (n=7)$ increased the plasma AVP from $3.8 \pm 0.8$ to $1,173.8 \pm 196.6 \mathrm{pg} / \mathrm{ml}$ in the venous effluents of the ispilateral arm of AVP infusion $(P$ $<0.01$ ).

Effects of L-arginine (Table I). Intraarterial infusion of $\mathrm{L}$ arginine at doses of $10 \mathrm{mg} / \mathrm{min}(n=7)$ increased the plasma

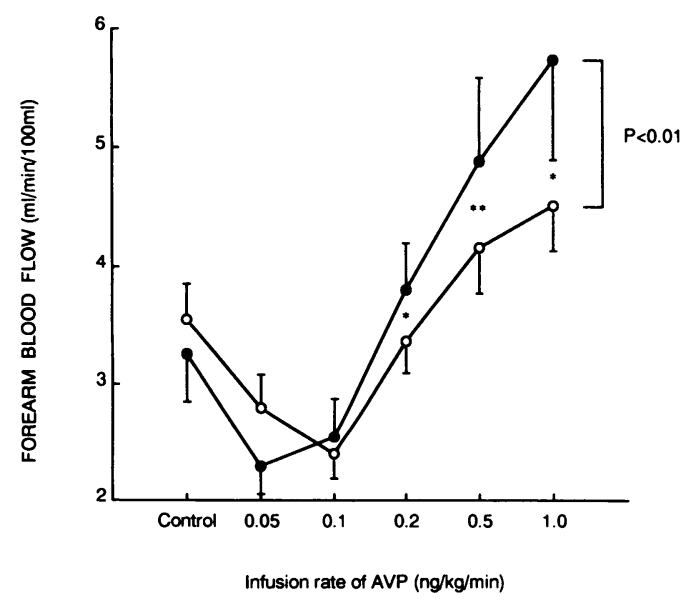

Figure 1. Line graph shows responses of FBF to intraarterial AVP during simultaneous infusion of saline $(O)$ or L-arginine at $10 \mathrm{mg} /$ $\min (\bullet)(n=8)$. ${ }^{\text {Indicates }} P<0.05$ and ${ }^{* *}$ indicates $P<0.01$.
L-arginine from $17 \pm 3$ to $602 \pm 65 \mu \mathrm{g} / \mathrm{ml}$ in the venous effluents of the ispilateral arm. Arterial pressure, heart rate, forearm blood flow, or forearm vascular resistance were not altered during infusion of $\mathrm{L}$-arginine at $10 \mathrm{mg} / \mathrm{min}$ (Table I).

After infusion of L-arginine, AVP caused biphasic changes in forearm blood flow as before $\mathrm{L}$-arginine $(P<0.01)$ (Fig. 1$)$ (Table I). Simultaneous infusion of L-arginine $(n=8)$ did not alter vasoconstrictor responses to intraarterial AVP at 0.05 and $0.1 \mathrm{ng} / \mathrm{kg}$ per min, but it augmented vasodilator responses at $0.2(P<0.05), 0.5(P<0.01)$, and $1.0 \mathrm{ng} / \mathrm{kg}$ per $\min (P$ $<0.05)$ (Fig. 1). Infusion of D-arginine $(10 \mathrm{mg} / \mathrm{min})$ did not alter baseline forearm hemodynamics (Table II) nor altered responses to graded infusions of AVP (Fig. 2).

Effect of L-NMMA (Tables III and IV). Intraarterial infusion of acetylcholine $(n=6)$ at doses of 4 and $12 \mu \mathrm{g} / \mathrm{min}$ increased forearm blood flow $(P<0.01)$ and decreased fore-

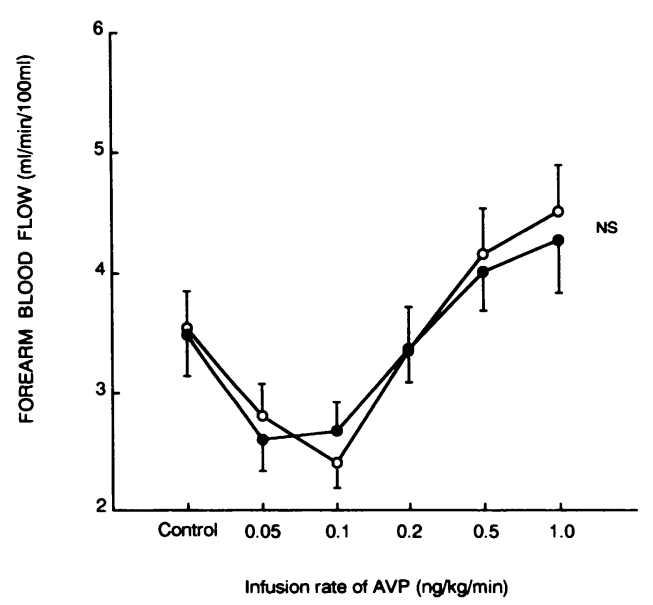

Figure 2. Line graph shows responses of FBF to AVP during simultaneous infusions of saline $(O)$ or D-arginine at $10 \mathrm{mg} / \mathrm{min}(\bullet)(n=8)$. 
Table II. Baseline Hemodynamics during Intraarterial Infusion of D-Arginine $(n=8)$

\begin{tabular}{lccc}
\hline & Control & D-arginine & $\begin{array}{c}P \text { by } \\
\text { one-way } \\
\text { ANOVA }\end{array}$ \\
\hline & & $10 \mathrm{mg} / \mathrm{min}$ & \\
MBP (mmHg) & $91 \pm 3$ & $88 \pm 4$ & NS \\
Heart rate (bpm) & $62 \pm 3$ & $59 \pm 3$ & NS \\
FBF (ml/min per 100 ml) & $3.5 \pm 0.3$ & $3.5 \pm 0.4$ & NS \\
FVR (U) & $26.4 \pm 1.7$ & $26.6 \pm 2.5$ & NS \\
& & & \\
\hline
\end{tabular}

Control, during infusion of saline. Values are mean \pm SEM.

arm vascular resistance $(P<0.01)$ dose dependently (Fig. 3 ). Arterial pressure or heart rate was not altered during infusion of acetylcholine ( Table III). Intraarterial infusion of L-NMMA $(n=6)$ at $4 \mu \mathrm{mol} / \mathrm{min}$ for $5 \mathrm{~min}$ decreased baseline forearm blood flow $(P<0.01)$ and increased forearm vascular resistance $(P<0.01)$ without changes in arterial pressure or heart rate (Table III). L-NMMA ( $4 \mu \mathrm{mol} / \mathrm{min}$ for $5 \mathrm{~min}$ ) partially but significantly blocked vasodilator responses to acetylcholine at doses of $4(P<0.01)$ and $12 \mu \mathrm{g} / \mathrm{min}(P<0.01)$ (Fig. 3).

Intraarterial infusion of AVP $(n=6)$ caused biphasic changes in forearm blood flow before L-NMMA (Fig. 4). Arterial pressure or heart rate was not altered during infusion of AVP (Table IV). Intraarterial infusion of L-NMMA $(n=6)$ at $4 \mu \mathrm{mol} / \mathrm{min}$ for $5 \mathrm{~min}$ decreased baseline forearm blood flow $(P<0.01)$ and increased forearm vascular resistance $(P$ $<0.01$ ) without changes in arterial pressure or heart rate ( Table IV). L-NMMA ( $4 \mu \mathrm{mol} / \mathrm{min}$ for $5 \mu \mathrm{min})$ significantly blocked vasodilator responses to AVP at doses of $0.5(P$ $<0.01)$ and $1.5 \mathrm{ng} / \mathrm{kg}$ per $\min (P<0.01)$ but did not affect vasoconstrictor responses to AVP at $0.1 \mathrm{ng} / \mathrm{kg}$ per $\min$ (Fig. 4).

Simultaneous infusions of L-arginine $(8 \mathrm{mg} / \mathrm{min}$ for $5 \mathrm{~min}-$ utes) and L-NMMA reversed the inhibitory effects of LNMMA on AVP-induced vasodilation $(P<0.05)$ (Fig. 5).

Control experiment (Table V). We carried out three vasopressin blood flow studies and obtained dose-response curves over a period of $2 \mathrm{~h}$ in the same subject without other drug treatment $(n=5)$. The three dose-response curves were similar (Fig. 6) (Table V).

\section{Discussion}

The major findings of this study were that in young healthy subjects, intraarterial infusion of L-arginine augmented AVPinduced vasodilation, that intraarterial infusion of L-NMMA blocked AVP-induced vasodilation, and that L-arginine reversed the inhibitory effects of L-NMMA. Thus our results suggest that AVP-induced vasodilation in the human forearm may be mediated by NO.

$A V P$-induced vasodilation. AVP is a potent vasoconstrictor in vitro. However, AVP does not produce the expected rise in blood pressure when given intravenously to intact animals (24, 25 ) or humans (26). Several mechanisms are considered to account for the discrepancy of the effects of AVP between in vivo and in vitro studies. These include withdrawal of the sym- pathetic tone because of several mechanisms $(27,28)$, negative inotropic and chronotropic action (29), and direct vasodilation (30). Previously, our research group and Hirsch et al. have shown that intraarterial infusion of AVP causes vasodilation in forearm vessels in humans $(3,4)$. In the present study, we also demonstrated the vasodilating effect of AVP.

In human forearms, AVP causes vasodilation only at high plasma concentrations ( 3 ). Although we measured the plasma level only at an infusion rate of $1.0 \mathrm{ng} / \mathrm{kg}$ per min, which increased the plasma level from 4 to $1,174 \mathrm{pg} / \mathrm{ml}$, the results in our previous study indicated that AVP appeared to cause vasodilation at plasma levels higher than $100-300 \mathrm{pg} / \mathrm{ml}(3)$. The vasodilating effects of intraarterially infused AVP is not caused by systemic effects since Hirsch and our research group have shown in previous studies that systemic concentration of AVP at which AVP causes vasodilation was low at $20 \mathrm{pg} / \mathrm{ml}$, and that the contralateral forearm blood flow was not altered $(3,4)$. Furthermore, arterial pressure or heart rate was not altered during infusion of AVP in the present and our previous studies (3).

AVP-induced vasodilation may be mediated by the V2 receptor. Hirsch et al. and our research group have demonstrated that the vasodilating effect of intraarterially infused AVP was potentiated after a specific intravenous or oral $\mathrm{V} 1$ receptor antagonist $(4,5)$. Furthermore, Hirsch et al. demonstrated that intraarterial infusion of a V2 agonist increased forearm blood flow and decreased forearm vascular resistance. Thus, AVP may cause vasodilation via the V2 receptor. However, other possibilities remain to be clarified.

Is AVP-induced vasodilation mediated by NO? In two different ways, we examined the possibility that AVP-induced vasodilation is mediated by NO; we determined whether supplementation of L-arginine augmented AVP-induced vasodilation and also determined whether L-NMMA inhibited AVP-induced vasodilation.

Table III. Forearm Vascular Responses to Intraarterial Infusion of Acetylcholine before and after $N^{G}$-Monomethyl-L-Arginine $(n=6)$

\begin{tabular}{lcccc}
\hline & Control & ACh & ACh & $\begin{array}{c}P \text { by } \\
\text { two-way ANOVA }\end{array}$ \\
& & $4 \mu \mathrm{mol} / \mathrm{min}$ & $12 \mu \mathrm{mol} / \mathrm{min}$ & \\
& & & & \\
MBP (mmHg) & & & & NS \\
Before L-NMMA & $89 \pm 3$ & $88 \pm 3$ & $88 \pm 3$ & \\
After L-NMMA & $89 \pm 4$ & $89 \pm 3$ & $88 \pm 3$ & NS \\
Heart rate (bpm) & & & & \\
Before L-NMMA & $63 \pm 4$ & $61 \pm 4$ & $61 \pm 5$ & \\
After L-NMMA & $60 \pm 4$ & $62 \pm 5$ & $59 \pm 4$ & \\
FBF (ml/min per 100 ml) & & & & \\
Before L-NMMA & $4.9 \pm 1.0$ & $12.7 \pm 3.1$ & $29.0 \pm 6.5$ & \\
After L-NMMA & $3.0 \pm 0.3$ & $5.0 \pm 1.6$ & $15.1 \pm 4.0$ & \\
FVR (U) & & & & \\
Before L-NMMA & $21.7 \pm 4.1$ & $9.0 \pm 2.3$ & $3.8 \pm 0.9$ & \\
After L-NMMA & $30.7 \pm 3.2$ & $23.9 \pm 5.0$ & $7.7 \pm 2.0$ & \\
Percent FVR & & & & \\
Before L-NMMA & 100 & $45 \pm 9$ & $21 \pm 7$ & \\
After L-NMMA & 100 & $80 \pm 15$ & $26 \pm 7$ & \\
& & & & \\
\hline
\end{tabular}

Control, during infusion of saline; $\mathrm{ACh}$, acetylcholine. Values are mean \pm SEM. 
Table IV. Forearm Vascular Responses to Intraarterial Infusion of Arginine Vasopressin before and after $N^{G}$-Monomethyl-L-Arginine $(n=6)$

\begin{tabular}{|c|c|c|c|c|c|}
\hline & Control & AVP & AVP & AVP & $\begin{array}{c}P \text { by } \\
\text { two-way } \\
\text { ANOVA }\end{array}$ \\
\hline & & $0.1 \mathrm{ng} / \mathrm{kg}$ per $\mathrm{min}$ & $0.5 \mathrm{ng} / \mathrm{kg}$ per min & $1.5 \mathrm{ng} / \mathrm{kg}$ per min & \\
\hline \multicolumn{6}{|l|}{ MBP (mmHg) } \\
\hline Before L-NMMA & $90 \pm 3$ & $89 \pm 4$ & $91 \pm 4$ & $92 \pm 3$ & \multirow{2}{*}{ NS } \\
\hline After L-NMMA & $91 \pm 3$ & $90 \pm 3$ & $91 \pm 3$ & $93 \pm 3$ & \\
\hline \multicolumn{6}{|l|}{ Heart rate (bpm) } \\
\hline Before L-NMMA & $60 \pm 4$ & $60 \pm 4$ & $59 \pm 4$ & $57 \pm 5$ & \multirow{2}{*}{ NS } \\
\hline After L-NMMA & $60 \pm 4$ & $59 \pm 4$ & $59 \pm 4$ & $61 \pm 6$ & \\
\hline \multicolumn{6}{|c|}{$\mathrm{FBF}(\mathrm{ml} / \mathrm{min}$ per $100 \mathrm{ml})$} \\
\hline Before L-NMMA & $4.6 \pm 1.0$ & $2.6 \pm 0.3$ & $5.5 \pm 0.5$ & $8.2 \pm 1.1$ & \multirow{2}{*}{$P<0.01$} \\
\hline After L-NMMA & $3.0 \pm 0.3$ & $2.2 \pm 0.3$ & $2.5 \pm 0.2$ & $3.3 \pm 0.4$ & \\
\hline \multicolumn{6}{|l|}{ FVR (U) } \\
\hline Before L-NMMA & $23.4 \pm 4.2$ & $35.5 \pm 3.6$ & $17.1 \pm 1.8$ & $12.1 \pm 1.6$ & \multirow{2}{*}{$P<0.01$} \\
\hline After L-NMMA & $30.9 \pm 2.8$ & $43.3 \pm 6.3$ & $37.7 \pm 3.2$ & $30.1 \pm 3.7$ & \\
\hline \multicolumn{6}{|l|}{ Percent FVR } \\
\hline Before L-NMMA & 100 & $168 \pm 25$ & $82 \pm 13$ & $57 \pm 9$ & \multirow{2}{*}{$P<0.01$} \\
\hline After L-NMMA & 100 & $143 \pm 23$ & $148 \pm 19$ & $126 \pm 15$ & \\
\hline
\end{tabular}

Control, during infusion of saline. Values are mean \pm SEM.

It is well known that L-arginine is a substrate of NO (6-9). Although L-arginine itself does not dilate normal vessels in the in vitro and in vivo animal studies, it has been shown that intravenous infusion of L-arginine decreases blood pressure in healthy humans $(31,32)$. Recently, we demonstrated in healthy young subjects that intraarterial infusion of $\mathrm{L}$-arginine dilated forearm blood vessels dose-dependently and augmented acetylcholine-induced vasodilation (14). The effects of L-arginine were not nonspecific because D-arginine (isomer of L-arginine) did not increase forearm blood flow nor augment acetylcholine-induced vasodilation (14). The systemic effects of L-arginine were excluded for the following reasons; absence of changes in forearm blood flow of the contralateral forearm

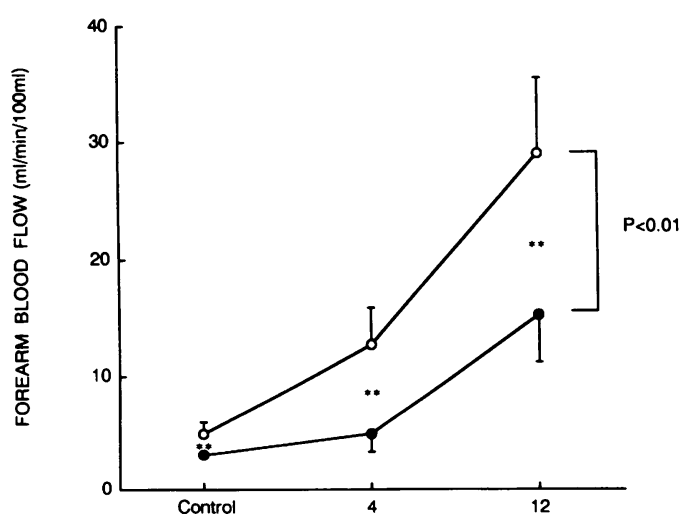

Infusion Rate of Ach ( $\mu \mathrm{g} / \mathrm{min})$

Figure 3. Line graph shows responses of FBF to acetylcholine before $(0)$ and after $(\bullet)$ infusion of L-NMMA $(n=6)$. ${ }^{* *}$ Indicates $P<0.01$. and low systemic concentration of L-arginine at high infusion rates (14). Furthermore, vasodilation in response to sodium nitroprusside (endothelium-independent vasodilator) was not altered by supplementation of L-arginine (14). Thus, our results may suggest that supplementation of $\mathrm{L}$-arginine facilitate the production of NO in human forearms.

In the same line of thinking, we examined possibility in this study that supplementation of L-arginine would augment AVP-induced vasodilation if AVP-induced vasodilation is mediated by NO. Intraarterial infusion of L-arginine at $10 \mathrm{mg}$ / min did not affect baseline forearm vascular resistance (FVR) or AVP-induced vasoconstriction, but augmented AVP-induced vasodilation. D-Arginine did not affect AVP-induced va-

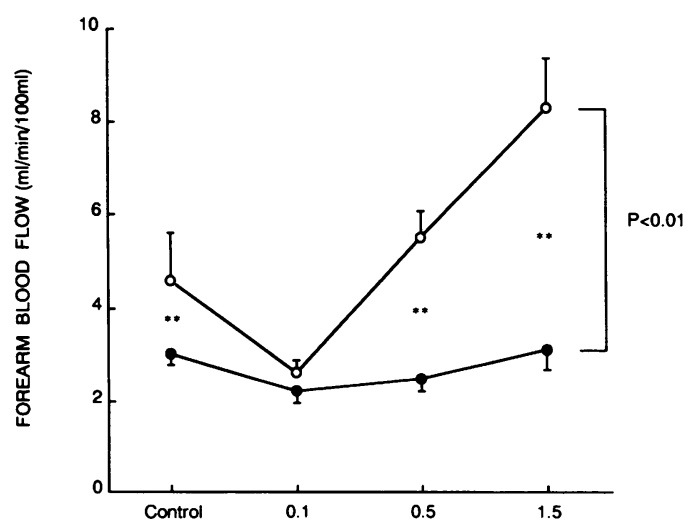

Infusion Rate of AVP ( $\mathrm{ng} / \mathrm{kg} / \mathrm{min})$

Figure 4. Line graph shows responses of FBF to AVP before $(0)$ and after $(\bullet)$ infusion of L-NMMA $(n=6)$. ${ }^{* *}$ Indicates $P<0.01$. 


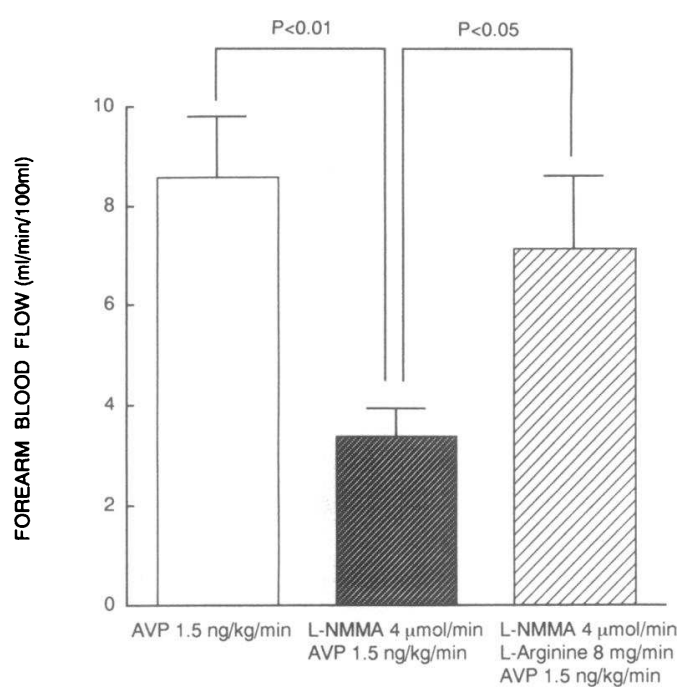

Figure 5. Bar graphs show responses FBF to AVP at doses of $1.5 \mathrm{ng} /$ $\mathrm{kg}$ per min before and after infusion of L-NMMA without or with L-arginine $(n=5)$.

soconstriction and vasodilation. These results suggest that AVP-induced vasodilation may be mediated by NO. To explore this possibility in a decisive way, we examined effects of L-NMMA (a specific blocker of the NO synthase) on AVP-induced vasodilation in the second protocol.

L-NMMA is an analogue of L-arginine and a blocker of the formation of NO from L-arginine in blood vessels $(33,34)$. L-NMMA that we used in this study was commercially available and purchased. To examine the potency of this compound in humans, we examined effects of this compound on acetyl-

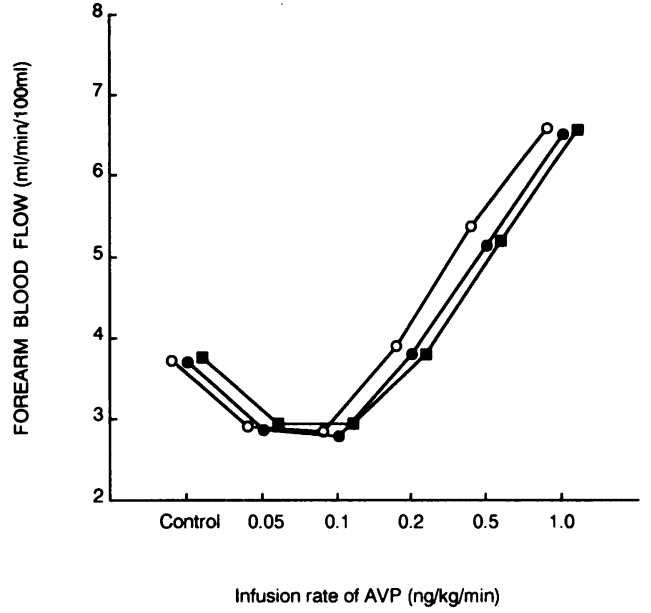

Figure 6. Line graph shows responses of FBF to intraarterial AVP at control (o), $1 \mathrm{~h}$ after the start of the experiment $(\bullet)$, or $2 \mathrm{~h}$ after the start of the experiment $(\square)(n=5)$.

choline-induced vasodilation in the human forearm. In this study, intraarterial infusion of L-NMMA at $4 \mu \mathrm{mol} / \mathrm{min}$ decreased baseline FVR significantly and completely inhibited vasodilation induced by intraarterial infusion of acetylcholine at $4 \mu \mathrm{g} / \mathrm{min}$. Our results are compatible with those by Vallance et al. (13). They showed that intraarterial infusion of $\mathrm{L}$ NMMA at $4 \mu \mathrm{mol} / \mathrm{min}$ for $5 \mathrm{~min}$ completely abolished vasodilation induced by intraarterial infusion of acetylcholine at 30 $\mathrm{nmol} / \mathrm{min}$ (about $5.5 \mu \mathrm{g} / \mathrm{min}$ ). Thus, L-NMMA that we used in this study possessed a high potency to inhibit NO synthesis. In both studies by our research group and Vallance et al., the inhibition of vasodilation in response to acetylcholine at high

Table V. Forearm Vascular Responses to Intraarterial Infusion of Arginine Vasopressin over a Period of $2 h(n=5)$

\begin{tabular}{|c|c|c|c|c|c|c|c|}
\hline & Control & AVP & AVP & AVP & AVP & AVP & $\begin{array}{c}P \text { by } \\
\text { two-way } \\
\text { ANOVA }\end{array}$ \\
\hline & & $0.05 \mathrm{ng} / \mathrm{kg}$ per min & $0.1 \mathrm{ng} / \mathrm{kg}$ per min & $0.2 \mathrm{ng} / \mathrm{kg}$ per min & $0.5 \mathrm{ng} / \mathrm{kg}$ per min & $1.0 \mathrm{ng} / \mathrm{kg} \mathrm{per} \mathrm{min}$ & \\
\hline \multicolumn{8}{|c|}{ MBP (mmHg) } \\
\hline Control & $92 \pm 2$ & $91 \pm 2$ & $91 \pm 2$ & $92 \pm 2$ & $93 \pm 2$ & $93 \pm 3$ & \\
\hline $1 \mathrm{~h}$ & $92 \pm 2$ & $91 \pm 2$ & $91 \pm 2$ & $92 \pm 2$ & $92 \pm 2$ & $93 \pm 2$ & NS \\
\hline $2 \mathrm{~h}$ & $92 \pm 2$ & $91 \pm 2$ & $92 \pm 2$ & $92 \pm 2$ & $93 \pm 2$ & $94 \pm 2$ & \\
\hline \multicolumn{8}{|c|}{ Heart rate (bpm) } \\
\hline Control & $62 \pm 5$ & $59 \pm 4$ & $60 \pm 4$ & $60 \pm 5$ & $60 \pm 4$ & $59 \pm 4$ & \\
\hline $1 \mathrm{~h}$ & $61 \pm 5$ & $59 \pm 4$ & $59 \pm 4$ & $59 \pm 3$ & $58 \pm 4$ & $58 \pm 4$ & NS \\
\hline $2 \mathrm{~h}$ & $60 \pm 5$ & $60 \pm 4$ & $64 \pm 4$ & $61 \pm 3$ & $61 \pm 3$ & $63 \pm 4$ & \\
\hline \multicolumn{8}{|c|}{ FBF $(\mathrm{ml} / \mathrm{min}$ per $100 \mathrm{ml})$} \\
\hline Control & $3.7 \pm 0.7$ & $2.9 \pm 0.5$ & $2.8 \pm 0.6$ & $3.9 \pm 1.0$ & $5.4 \pm 1.2$ & $6.6 \pm 2.0$ & \\
\hline $1 \mathrm{~h}$ & $3.7 \pm 0.6$ & $2.9 \pm 0.4$ & $2.8 \pm 0.5$ & $3.8 \pm 0.8$ & $5.1 \pm 1.3$ & $6.5 \pm 1.9$ & NS \\
\hline $2 \mathrm{~h}$ & $3.7 \pm 0.7$ & $2.9 \pm 0.5$ & $2.9 \pm 0.5$ & $3.8 \pm 0.9$ & $5.1 \pm 1.2$ & $6.5 \pm 1.9$ & \\
\hline \multicolumn{8}{|l|}{ FVR (U) } \\
\hline Control & $29.3 \pm 7.7$ & $37.5 \pm 10.5$ & $39.8 \pm 13.0$ & $29.9 \pm 8.9$ & $20.3 \pm 4.7$ & $17.6 \pm 3.7$ & \\
\hline $1 \mathrm{~h}$ & $27.5 \pm 5.3$ & $34.8 \pm 6.6$ & $37.3 \pm 8.6$ & $29.2 \pm 8.0$ & $21.9 \pm 5.1$ & $17.3 \pm 3.4$ & NS \\
\hline $2 \mathrm{~h}$ & $28.7 \pm 6.7$ & $35.6 \pm 7.7$ & $36.6 \pm 8.8$ & $30.4 \pm 8.6$ & $21.3 \pm 4.5$ & $17.5 \pm 3.5$ & \\
\hline
\end{tabular}

Control, during infusion of saline. Values are mean \pm SEM. 
doses was partial (13). Several possibilities are considered. Since acetylcholine dilates blood vessels by three different mechanisms; a release of NO from the endothelium (35-37), prejunctional inhibition of adrenergic neurotransmission (38, 39 ), and a release of prostacyclin from blood vessels $(36,37)$, the partial inhibition of vasodilation induced by high doses of acetylcholine may not be caused by inadequate potency of this compound. It is possible that the acetylcholine-induced vasodilation might have been completely inhibited if we had used a larger dose of L-NMMA for longer periods.

Intraarterial infusion of L-NMMA did not affect AVP-induced vasoconstriction, but completely abolished AVP-induced vasodilation (Fig. 4). These results strongly suggest that AVP-induced vasodilation in the human forearm is mediated by NO. We further tested possibility by determining the effects of simultaneous infusions of L-arginine and L-NMMA on AVP-induced vasodilation. Simultaneous infusion of L-arginine reversed the inhibitory effects of L-NMMA on AVP-induced vasodilation (Fig. 5). Taken together, AVP-induced vasodilation in the human forearm is most likely mediated by NO converted from $L$-arginine.

Although we did multiple AVP infusions, we do not think that one dose response curve affected subsequent dose-response curves because we performed control experiments in which three dose-response curves to AVP were obtained and similar.

Physiological and pathophysiological implications. The vasodilatory response to AVP is only at high concentrations. Thus, physiological meanings may not be clear. Nonetheless, our finding may be important to consider the role of endothelium in control of vascular tone. In animals, it has been shown that the AVP receptor is present in the endothelium and AVP releases NO to cause vasodilation. Our findings clearly demonstrated that AVP release NO and causes vasodilation in humans, suggesting a presence of AVP receptor in the endothelium.

AVP causes vasodilation at higher concentrations $>300$ $\mathrm{pg} / \mathrm{ml}$. This high level of plasma AVP concentration is not reached in the normal or pathological state, such as hypertension or heart failure. However, plasma AVP concentration would increase $>300 \mathrm{pg} / \mathrm{ml}$ when massive hemorrhage occurs, in which severe vasoconstriction supervenes. Released AVP at high concentrations into circulation may counteract severe vasoconstriction in the case of massive hemorrhage.

Finally, the V2 receptor may mediate production of NO in the human forearm and cause vasodilation. We did not explore this possibility in the present study.

In summary, we demonstrated in young healthy humans that intraarterial infusion of L-arginine augmented AVP-induced vasodilatation, that intraarterial infusion of L-NMMA blocked AVP-induced vasodilatation, and that L-arginine reversed the inhibitory effects of L-NMMA. Our results suggest that AVP causes vasodilatation via production of NO from L-arginine in forearm vessels of humans.

\section{Acknowledgments}

We thank Ms. Fumiko Amano for her technical assistance. We express appreciation to Drs. Daisuke Teshima and Osamu Fujishita from the pharmacological section for preparing drugs.

This study was supported by a Grant-in-aid for General Scientific
Research and by a Grant-in-Aid for Scientific Research on Priority Areas from the Japanese Ministry of Education, Science, and Culture.

\section{References}

1. Share, L. 1988. Role of vasopressin in cardiovascular regulations. Physiol. Rev. 68:1248-1284

2. Altura, B. M., and B. T. Altra. 1977. Vascular smooth muscle and neurohypophyseal hormones. Fed. Proc. 36:1853-1860.

3. Suzuki, S., A. Takeshita, T. Imaizumi, Y. Hirooka, M. Yoshida, S. Ando, and M. Nakamura. 1989. Biphasic forearm vascular responses to intraarterial arginine vasopressin. J. Clin. Invest. 84:427-434.

4. Hirsch, A. T., V. J. Dzau, J. A. Majzoub, and M. A. Creager. 1989. Vasopressin-mediated forearm vasodilation in normal humans. Evidence for a vascular vasopressin V2 receptor. J. Clin. Invest. 84:418-426.

5. Imaizumi, T., S. Harada, Y. Hirooka, H. Masaki, M. Momohara, and A. Takeshita. 1992. Effects of OPC-21268, an orally effective vasopressin $\mathrm{V}_{1}$ receptor antagonist in humans. Hypertension (Dallas). 20:54-58.

6. Palmer, R. M. J., D. S. Ashton, and S. Moncada. 1988. Vascular endothelial cells synthesize nitric oxide from L-arginine. Nature (Lond.). 333:664-666.

7. Palmer, R. M. J., D. D. Rees, D. S. Ashton, and S. Moncada. 1988. L-Arginine is the physiological precursor for the formation of nitric oxide in the endothelium-dependent relaxation. Biochem. Biophys. Res. Commun. 153:1251-1256.

8. Palmer, R. M. J., and S. Moncada. 1989. A novel citrulline-forming enzyme implicated in the formation of nitric oxide by vascular endothelial cells. Biochem. Biophys. Res. Commun. 158:348-352.

9. Mayer, B., K. Schmidt, P. Humbert, and E. Böhme. 1989. Biosynthesis of endothelium-derived relaxing factor: a cytosolic enzyme in porcine aortic endothelial cells $\mathrm{Ca}^{2+}$-dependently converts $\mathrm{L}$-arginine into an activator of soluble guanylyl cyclase. Biochem. Biophys. Res. Commun. 164:678-685.

10. Ignarro, L. J. 1989. Biological actions and properties of endothelium-derived nitric oxide formed and released from artery and vein. Circ. Res. 65:1-21.

11. Ignarro, L. J. 1990. Nitric oxide, A novel signal transduction mechanisms for trans-cellular communication. Hypertension (Dallas). 16:477-483.

12. Kelm, M., and J. Schrader. 1990. Control of vascular tone by nitric oxide. Circ. Res. 66:1561-1575.

13. Vallance, P., J. Collier, and S. Moncada. 1989. Effects of endotheliumderived nitric oxide on peripheral arteriolar tone in man. Lancet. ii:997-1000.

14. Imaizumi, T., Y. Hirooka, H. Masaki, S. Harada, M. Momohara, T. Tagawa, and A. Takeshita. 1992. Effects of L-arginine on forearm vessels and responses to acetylcholine. Hypertension (Dallas). 20:511-517.

15. Katusic, Z. S., J. T. Shepherd, and P. M. Vanhoutte. 1984. Vasopressin causes endothelium-dependent relaxation of the canine basilar artery. Circ. Res. 55:575-579.

16. Katusic, Z. S., J. T. Shepherd, and P. M. Vanhoutte. 1986. Oxytcrin causes endothelium-dependent relaxation of the canine basilar artery by activating V1-vasopressinergic receptors. J. Pharmacol. Exp. Ther. 236:166-170.

17. Schini, V. B., Z. S. Katusic, and P. M. Vanhoutte. 1990. Neurohypophyseal peptides and tachykinins stimulate the production of cyclic GMP in cultured porcine aortic endothelial cells. J. Pharmacol. Exp. Ther. 255:994-1000.

18. Katusic, Z. S. 1992. Endothelial L-arginine pathway and regional cerebral arterial reactivity to vasopressin. Am. J. Physiol. 262:H1557-H1562.

19. Imaizumi, T., A. Takeshita, T. Ashihara, and M. Nakamura. 1985. The effects of sublingually administered nitroglycerin on forearm vascular resistance in patients with heart failure and normal subjects. Circulation. 72:747-752.

20. Imaizumi, T., A. Takeshita, S. Suzuki, M. Yoshida, S. Ando, and M. Nakamura. 1990. Age-independent forearm vasodilatation by acetylcholine and adenosine 5'-triphosphate in humans. Clin. Sci. 78:89-93.

21. Watabe, T., K. Tanaka, M. Kumagae, S. Itoh, M. Kogure, F. Takeda, K. Morio, M. Hasegawa, T. Horiuchi, S. Miyabe, and N. Shimizu. 1987. Hormonal responses to insulin-induced hypoglycemia in man. J. Clin. Endocrinol. \& Metab. 65:1187-1191.

22. Watabe, T., K. Tanaka, M. Kumagae, S. Itoh, M. Kogure, M. Hasegawa, T. Horiuchi, K. Morio, F. Takeda, E. Ubukata, S. Miyabe, and N. Shimizu. 1988. Role of endogenous arginine vasopressin in potentiating corticotropin-releasing hormone-stimulated corticotropin secretion in man. J. Clin. Endocrinol. \& Metab. 66:1132-1137.

23. Lee, P. L. Y., and R. H. Slocum. 1988. A high-resolution method for amino acid analysis of physiological fluid containing mixed disulfides. Clin Chem. 34:719-723.

24. Cowley, A. W., E. Monos, and A. C. Guyton. 1974. Interaction of vasopressin and baroreceptor reflex system in the regulation of arterial blood pressure in the dog. Circ. Res. 34:505-514.

25. Montani, J. P., J. R. Liard, J. Schoun, and J. Mohring. 1980. Hemodynamic effects of exogenous and endogenous vasopressin at low plasma concentrations in conscious dog. Circ. Res. 47:346-355.

26. Kitchin, A. H. 1957. The effect of pitressin on hand and forearm blood flow. Clin. Sci. 16:639-644. 
27. Imaizumi, T., and M. D. Thames. 1986. Influence of intravenous and intracerebro-ventricular vasopressin on baroreflex control of renal nerve traffic. Circ. Res. 58:17-25.

28. Suzuki, S., A. Takeshita, T. Imaizumi, Y. Hirooka, M. Yoshida, S. Ando, and M. Nakamura. 1989. Central nervous system mechanisms involved in inhibition of renal sympathetic nerve activity induced by arginine vasopressin. Circ. Res. 65:1390-1399.

29. Share, L. 1988. Role of vasopressin in cardiovascular regulation. Physiol. Rev. 68:1248-1284.

30. Walker, B. R. 1986. Evidence for a vasodilatory effect of vasopressin in the conscious rats. Am. J. Physiol. 251:H34-H39.

31. Hishikawa, K., T. Nakaki, H. Suzuki, T. Saruta, and R. Kato. 1991. L-Arginine-induced hypotension. Lancet. 337:683-684.

32. Hishikawa, K., T. Nakaki, M. Tsuda, H. Esumi, H. Ohshima, H. Suzuki, T. Saruta, and R. Kato. 1992. Effect of systemic L-arginine administration on hemodynamics and nitric oxide release in man. Jpn. Heart J. 33:41-48.

33. Sakuma, I., D. J. Stuehr, S. S. Gross, C. Nathan, and R. Levi. 1988. Identification of arginine as a precursor of endothelium-derived relaxing factor. Proc. Natl. Acad. Sci. USA. 85:8664-8667.
34. Moncada, S., M. R. J. Palmer, and E. A. Higgs. 1989. Biosynthesis of nitric oxide from L-arginine. A pathway for the regulation of cell function and communication. Biochem. Pharmacol. 38:1709-1715.

35. Furchgott, R. F., and J. V. Zawadzki. 1980. The obligatory role of endothelial cells in the regulation of arterial smooth muscle by acetylcholine. Nature (Lond.). 288:373-376.

36. Gryglewski, R. J., R. M. Botting, and J. Vane. 1988. Mediators produced by the endothelial cell. Hypertension (Dallas). 12:530-548.

37. Vanhoutte, P. M. 1989. Endothelium and control of vascular function: state of art lecture. Hypertension (Dallas). 13:658-667.

38. Vanhoutte, P. M., and M. N. Lewy. 1980. Prejunctional cholinergic modulation of adrenergic neurotransmission in the cardiovascular system. Am. J. Physiol. 238:H275-H281.

39. Vanhoutte, P. M., and T. F. Lüscher. 1986. Peripheral mechanisms in cardiovascular regulation: transmitters, receptors, and the -endothelium. In Handbook of Hypertension, Volume 8: Physiology and Pathophysiology of $\mathrm{Hy}$ pertension-Regulatory Mechanisms. R. C. Tarazi and A. Zanchetti, editors. Elsevier Amsterdam. Elsevier. pp. 96-123. 